\title{
Cassane Diterpenes from Plathymenia reticulata
}

\author{
Rosélia de S. Leal, Mary Anne S. Lima and Edilberto R. Silveira* \\ Departamento de Química Orgânica e Inorgânica, Centro de Ciências, Universidade Federal do Ceará, \\ CP 12200, 60021-970 Fortaleza-CE, Brazil
}

\begin{abstract}
Do lenho do caule de Plathymenia reticulata (Leguminosae) foram isolados dois novos diterpenos cassânicos: 16,18-diacetoxicass-13(15)-eno e 16-hidroxi-18-acetoxicass-13(15)-eno, além dos conhecidos diterpenos platiterpol, acetato de vinhaticila e vinhaticoato de metila. As estruturas foram determinadas com base em análise espectroscópica, envolvendo comparação com dados da literatura e transformações químicas.
\end{abstract}

From trunk heartwood of Plathymenia reticulata (Leguminosae) two novel cassane diterpenes 16,18-diacetoxycass-13(15)-ene and 16-hydroxy-18-acetoxycass-13(15)-ene, and the known diterpenes plathyterpol, vinhaticyl acetate and methyl vinhaticoate were isolated. Structure determinations were accomplished by spectroscopic analysis involving comparison with data from literature and chemical transformations.

Keywords: Plathymenia reticulata, Leguminosae, cassane diterpenes, 16,18-diacetoxycass13(15)-ene, 16-hydroxy-18-acetoxycass-13(15)-ene, ${ }^{13} \mathrm{C}$ NMR data

\section{Introduction}

According to Bentham, ${ }^{1}$ the genus Plathymenia (Leguminosae) comprises two species: $P$. reticulata and $P$. foliolosa. In the course of our continuing studies of the secondary metabolites from the trunk heartwood of $P$. reticulata, we now report the isolation and a structural elucidation of two novel cassane diterpenes characterized as 16,18-diacetoxycass-13(15)-ene (1) and 16-hidroxy-18acetoxycass-13(15)-ene (2), and isolation of three previously reported compounds plathyterpol ${ }^{1}(\mathbf{3})$, vinhaticyl acetate (4) and methyl vinhaticoate $(5){ }^{2}$ The spectroscopic data of compound $\mathbf{5}$ and of the derivatives $\mathbf{6}$ to $\mathbf{1 0}$, are described for the first time.

\section{Results and Discussion}

Silica gel chromatography of the hexane extract obtained from the trunk heartwood of Plathymenia reticulata, yielded five compounds $\mathbf{1}$ to $\mathbf{5}$.

Compound 1, a colorless solid ( $\mathrm{mp} 69-71^{\circ} \mathrm{C}$ ), showed a $\left[\mathrm{M}^{+}\right]$at $\mathrm{m} / \mathrm{z}, 390$, compatible with a molecular formula $\mathrm{C}_{24} \mathrm{H}_{38} \mathrm{O}_{4}$. The ${ }^{1} \mathrm{H}$ NMR spectrum showed resonances corresponding to two methyl groups attached to a

* e-mail: edil@ufc.br

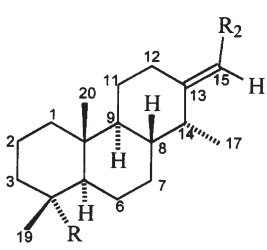

$1 \mathrm{R}_{1}, \mathrm{R}_{2}=\mathrm{CH}_{2} \mathrm{OAc}$ $2 \mathrm{R}_{1}=\mathrm{CH}_{2} \mathrm{OAc}, \mathrm{R}_{2}=\mathrm{CH}_{2} \mathrm{OH}$ $6 \mathrm{R}_{1}, \mathrm{R}_{2}=\mathrm{CH}_{2} \mathrm{OH}$

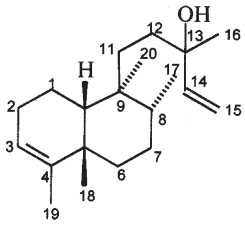

3

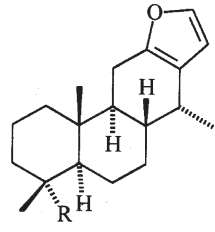

$4 \mathrm{R}=\mathrm{CH}_{2} \mathrm{OAc}$

$$
\begin{aligned}
& \mathbf{8 R}=\mathrm{CH}_{2} \mathrm{OAc} \\
& \mathbf{8 R}=\mathrm{CH}_{2} \mathrm{OH} \\
& 10 \mathrm{R}=\mathrm{CO}_{2} \mathrm{CH}_{3}
\end{aligned}
$$

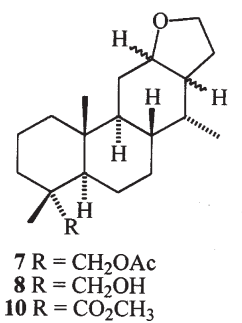

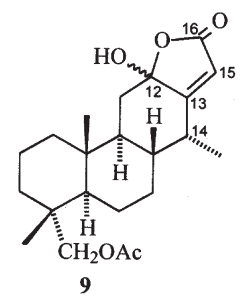

quaternary carbon at $\delta 0.83(\mathrm{~s}, 6 \mathrm{H})$, one methyl group attached to a methine carbon at $\delta 0.93(\mathrm{~d}, 3 \mathrm{H}, J 7.0 \mathrm{~Hz})$ and two other methyl groups as singlets at $\delta 1.96(\mathrm{~s}, 3 \mathrm{H})$ and $\delta$ $1.93(\mathrm{~s}, 3 \mathrm{H})$, corresponding to two acetyl groups. The IR absorptions at 1720 and $1710 \mathrm{~cm}^{-1}$, characteristic of carbonyl groups of ester in addition to the $\mathrm{C}-\mathrm{O}$ stretching at $1230 \mathrm{~cm}^{-1}$, corroborated to identify the presence of two acetoxy moieties.

The proposition of one acetoxy group, as part of an allylic system, was suggested by the deshielded signal of the 
methylene hydrogens at $\delta 4.36$ (d, 2H, J 7.0 Hz, C-16), probably attached to a heteroatom, and vicinally coupled to the hydrogen of a trisubstituted double bond at $\delta 5.33(\mathrm{t}$, $1 \mathrm{H}, J 7.0 \mathrm{~Hz}, \mathrm{C}-15)$. The presence of an AB system at $\delta 3.55$ (d, $1 \mathrm{H}, J 11.0 \mathrm{~Hz}, \mathrm{H}-18 \mathrm{~b})$ and 3.70 (d, 1H, J11.0 Hz, H-18a) was indicative of an acetylated carbinolic methylene group adjacent to an asymmetric center (C-4). These observations, in conjunction with the cross-peak correlation observed on the ${ }^{1} \mathrm{H}-{ }^{1} \mathrm{H}$ COSY experiment between the hydrogen at $\delta 4.36$ with the hydrogen at $\delta 5.33$, and the hydrogen at $\delta 3.55$ with the hydrogen at $\delta 3.70$ respectively, were all consistent with this proposition.

Chemical shifts and comparative analysis of $\mathrm{BB}$ and DEPT $-{ }^{13} \mathrm{C}$ NMR (Table 1) spectra revealed 24 lines in agreement with the suggested molecular formula. From these data one can easily deduce the presence of acetate portions at $\delta 171.1$ and $\delta 171.3$, the unsaturated carbons at $\delta 151.8$ and $\delta 113.7$, two carbinolic methylenes at $\delta 60.8$ and $\delta 73.3$, and 18 saturated carbon signals (5 methyls, 7 methylenes, 4 methines and 2 quaternaries). The unambiguous assignment of all carbon (Table 1) and hydrogens was possible by the HETCOR spectrum analysis. The correlations of the carbinolic methylenes at $\delta 60.8$ with the hydrogen at $\delta 4.36$ and at $\delta 73.3$ with the hydrogens at $\delta 3.55$ and $\delta 3.70$, as well as the correlation between the unsaturated methine at $\delta 113.7$ with the hydrogen at $\delta 5.33$ were visualized.

Table 1. ${ }^{13} \mathrm{C}$ NMR (75 MHz) spectral data for diterpenes $\mathbf{1}, \mathbf{4}, \mathbf{5}$ and $\mathbf{8}$ to $\mathbf{1 0}$ in $\mathrm{CDCl}_{3}$

\begin{tabular}{rrrrrrr}
\hline $\mathbf{C}$ & \multicolumn{1}{c}{$\mathbf{1}^{\mathrm{a}}$} & $\mathbf{4}^{\mathrm{b}}$ & \multicolumn{1}{c}{$\mathbf{5}^{\mathrm{c}}$} & $\mathbf{8}$ & $\mathbf{9}^{\mathrm{d}}$ & $\mathbf{1 0}^{\mathrm{e}}$ \\
\hline 1 & 39.2 & 39.2 & 35.7 & 38.9 & 38.0 & 36.9 \\
2 & 18.1 & 18.1 & 18.2 & 18.1 & 18.0 & 18.0 \\
3 & 35.9 & 35.9 & 36.9 & 35.3 & 35.8 & 35.0 \\
4 & 36.8 & 37.4 & 47.6 & 37.7 & 36.6 & 47.6 \\
5 & 49.6 & 49.5 & 49.8 & 48.7 & 49.0 & 49.9 \\
6 & 31.2 & 31.1 & 31.0 & 31.7 & 30.4 & 31.5 \\
7 & 21.7 & 21.7 & 24.2 & 21.7 & 21.5 & 24.5 \\
8 & 40.4 & 35.7 & 35.8 & 38.4 & 36.9 & 35.0 \\
9 & 48.3 & 45.8 & 45.8 & 42.1 & 45.1 & 42.3 \\
10 & 36.6 & 36.6 & 37.1 & 36.6 & 38.9 & 36.4 \\
11 & 23.8 & 22.4 & 22.2 & 26.5 & 21.5 & 26.2 \\
12 & 26.4 & 149.8 & 149.8 & 78.3 & 106.5 & 78.1 \\
13 & 151.8 & 122.6 & 122.6 & 35.2 & 173.6 & 35.0 \\
14 & 44.1 & 31.6 & 31.6 & 41.9 & 40.7 & 41.9 \\
15 & 113.7 & 109.7 & 109.7 & 30.0 & 113.1 & 30.0 \\
16 & 60.8 & 140.5 & 140.5 & 66.5 & 173.6 & 66.2 \\
17 & 14.3 & 17.7 & 17.8 & 16.7 & 13.0 & 11.0 \\
18 & 73.3 & 73.5 & 179.0 & 72.4 & 73.2 & 179.3 \\
19 & 17.8 & 18.0 & 17.2 & 18.1 & 18.0 & 17.1 \\
20 & 14.9 & 15.1 & 14.8 & 15.0 & 14.8 & 14.5 \\
\hline
\end{tabular}

${ }^{a} \delta 171.1$ and $\delta 171.3\left(\mathrm{H}_{3} \mathrm{C}-\underline{\mathrm{C}}=\mathrm{O}\right), \delta 21.1$ and $\delta 21.0\left(\underline{\mathrm{CH}}_{3}-\mathrm{C}=\mathrm{O}\right)$;

b $\delta 171.6\left(\mathrm{CH}_{3}-\underline{\mathrm{C}}=\mathrm{O}\right)$ and $\delta 21.2\left(\mathrm{CH}_{3}-\mathrm{C}=\mathrm{O}\right) ;{ }^{c} \delta 51.9\left(\mathrm{OCH}_{3}\right)$;

d $\delta 171.5\left(\mathrm{H}_{3} \mathrm{C}-\underline{\mathrm{C}}=\mathrm{O}\right)$ and $\delta 21.0\left(\underline{\mathrm{CH}}_{3}-\mathrm{C}=\mathrm{O}\right)$; ${ }^{\mathrm{e}} \delta 51.7\left(\mathrm{OCH}_{3}\right)$.
The molecular formula $\mathrm{C}_{24} \mathrm{H}_{38} \mathrm{O}_{4}$ requires six degrees of unsaturation. Since two carbonyls and a double bond account for three of them, the remaining three unsaturation indicate the tricyclic character of $\mathbf{1}$.

Based on the above evidences, as well as analysis of analogous substances isolated from this genus, ${ }^{1,2}$ the structure of a cassane diterpene does fit the data for compound $\mathbf{1}$. The observed mass spectrum fragmentation pattern is in agreement with the proposed structure for $\mathbf{1}$. The fragment at $m / z 330$ (1a) could be explained by elimination of acetic acid from either the allylic moiety or the carbinolic methylene, while the most stable fragment at $m / z 257$ (1b) confirmed the diacetylated character of $\mathbf{1}$ (Scheme 1).

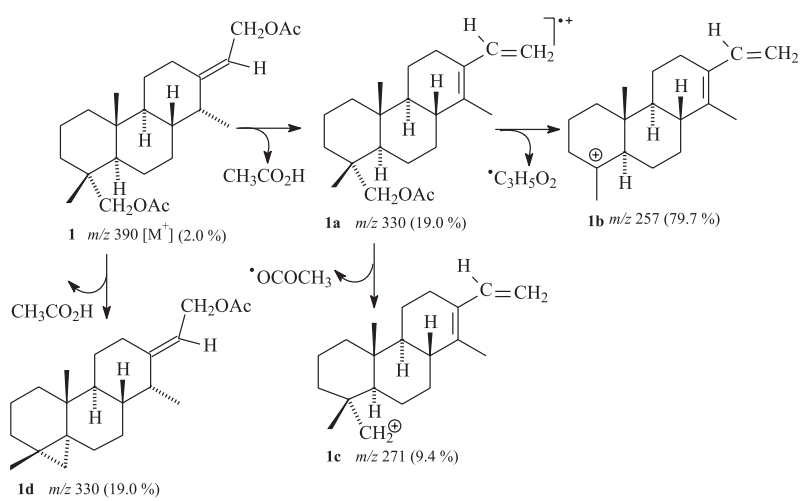

Scheme 1. Proposed fragmentation pattern of $\mathbf{1}$ in the mass spectrometer, suggesting its diacetate character.

Reduction of 1 with $\mathrm{LiAlH}_{4}$ yielded solid $\mathbf{6}$ whose IR spectrum showed a broad band at $3400 \mathrm{~cm}^{-1}$ corresponding to the free hydroxyls, and the absence of carbonyl absorptions at 1720 and $1710 \mathrm{~cm}^{-1}$. The ${ }^{1} \mathrm{H}$ NMR spectrum of 6 indeed revealed the expected protection of the carbinol methylene of the AB system at $\delta 3.00(1 \mathrm{H}, \mathrm{d}, J 11.0 \mathrm{~Hz})$ and $3.20(1 \mathrm{H}, \mathrm{d}, J 11.0 \mathrm{~Hz})$ and of the allylic methylene at $\delta 4.03(2 \mathrm{H}, \mathrm{d}, J 7.0 \mathrm{~Hz}$ ). Except for the absence of methyl groups at $\delta 1.96$ and $\delta 1.93$, all other signals of the ${ }^{1} \mathrm{H}$ NMR spectrum of $\mathbf{6}$ resembles that of observed for $\mathbf{1}$. These results, in addition to the biogenetic pattern observed for the major compound, $4,{ }^{2}$ of this plant, support the assignment of structure of $\mathbf{1}$ as 16,18-diacetoxycass-13 (15)-ene, a new cassane diterpene.

The final structure for $\mathbf{1}$, including the relative stereochemistry, was based on comparison of the ${ }^{13} \mathrm{C}$ NMR data (Table 1) of $\mathbf{1}$ and $\mathbf{4}$, the later isolated previously from the same source which had its structure established by Xray crystallography. ${ }^{3}$ Moreover the chemical shift for $\mathrm{C}$ $18(\delta 73.3)$ is in agreement with the equatorial orientation of the acetylated oxymethylene (C-18). An axial orientation 
for that moiety would shield C-19 $(\sim \delta$ 65.3) as already observed by Godoy et al. for vouacapenol. ${ }^{4}$ The chemical shift differences just for C-8, C-9, C-14 and C-17 in $\mathbf{1}$ relative to 4 could be explained by a conjunction of effects of the ring strain release after opening of the furan ring, the correspondent disappearance of the $\gamma$-effect of the oxygen at C-12 or yet by the "endocyclic homoallyl effect", alleged by Wenkert et al. ${ }^{5}$ The suggested ${ }^{13} \mathrm{C}$ NMR data assignment was done based on the HMQC and HMBC spectral analysis. For example, the methyl group at $\delta_{\mathrm{H}} 0.96(\delta 15.1, \mathrm{C}-20)$ did correlate to a quaternary carbon at $\delta 36.6$ (C-10), a methylene at $\delta 39.2(\mathrm{C}-1)$, and two methynes at $\delta 45.8(\mathrm{C}$ $9)$ and $\delta 49.5(\mathrm{C}-5)$. The methyl group at $\delta_{\mathrm{H}} 0.84(\delta 18.0$, $\mathrm{C}-19)$ correlated to a quaternary carbon at $\delta 37.4(\mathrm{C}-4)$, a methylene at $\delta 35.9(\mathrm{C}-3)$ and also to the methyne at $\delta 49.5$ (C-5), and finally the methyl at $\delta_{\mathrm{H}} 0.98(\delta 17.2, \mathrm{C}-$ 17) correlated to two methynes at $\delta 35.7$ (C-8) and 31.6 (C-14). Table 1 does present all other observed correlations.

Compound 2, obtained as a colorless oil, showed $\left[\mathrm{M}^{+}\right]$ at $m / z, 348(2.0 \%)$. The IR spectrum revealed the presence of a free hydroxyl group as a broad band at $3400 \mathrm{~cm}^{-1}$, one carbonyl group at $1715 \mathrm{~cm}^{-1}$ and a double bond at 1660 $\mathrm{cm}^{-1}$. The ${ }^{1} \mathrm{H}$ NMR data of 2 was similar to that recorded for 1 , except for the presence of only one acetoxy group at $\delta$ $2.01(3 \mathrm{H}, \mathrm{s})$. The downfield region in the ${ }^{1} \mathrm{H}$ NMR spectrum was crowded as in the spectrum of compound 1, except for the absorption at $\delta 3.93(2 \mathrm{H}, \mathrm{d}, J 7.0 \mathrm{~Hz})$, corresponding to the allylic methylene $\mathrm{H}-16$ attached to a hydroxyl group, as observed previously in $\mathbf{6}$.

These results allowed to establish 2 as the 16-hydroxy18-acetoxycass-13(15)-ene, a new cassane diterpene which contains an allylic alcohol and an acetylated carbinolic methylene group attached to an asymmetric center. In order to confirm the structure proposal, compound $\mathbf{2}$ was acetylated with acetic anhydride and pyridine to yield a product identical to $\mathbf{1}$. Reduction of $\mathbf{2}$ with $\mathrm{LiAlH}_{4}$ yielded also the diol 6, already obtained from $\mathbf{1}$, confirming the presence of the monoacetate group.

The known diterpenes previously described for the same plant species, plathyterpol (3), vinhaticyl acetate (4), and the major constituent methyl vinhaticoate $(\mathbf{5}),{ }^{2}$ whose pharmacological investigations have demonstrated its spasmolitic effect, ${ }^{3}$ were also isolated. Their physical and spectral data were in agreement with those reported in the literature, ${ }^{1-4}$ and the ${ }^{13} \mathrm{C}$ NMR data of compound 5 are described for the first time (Table 1).

Pursuing the preparation of new cassane derivatives, compounds $\mathbf{7}$ to $\mathbf{1 0}$ were also prepared for biological tests purposes and for spectral analysis (Table 1).

Hydrogenation of $\mathbf{4}$ yielded compounds $\mathbf{7}$ and $\mathbf{8}$, that were separated by $\mathrm{SiO}_{2}$ chromatography. The less polar product obtained as an yellow oil, showed IR absorption at $1710 \mathrm{~cm}^{-1}$ characteristic of carbonyl group of ester moiety and the disappearance of the absorptions related to the furan ring, in comparison with 4 . This information was confirmed by ${ }^{1} \mathrm{H}$ NMR analysis by absence of the two doublets in the downfield region characteristic of the disubstituted furan ring. The presence of fragments at $\mathrm{m} / \mathrm{z}$ 97 (7a) and $\mathrm{m} / z, 165$ (7b) in the mass spectrum does agree with compound 7 as the tetrahydrogenated derivate (Scheme 2). The more polar product obtained as a colorless solid, mp 124-125 ${ }^{\circ} \mathrm{C}$, revealed the presence of a free hydroxyl group as a broad band at $3400 \mathrm{~cm}^{-1}$ and the absence of signals corresponding to the carbonyl group and furan ring in the IR spectrum when compared with 4. This information in conjunction with the absence of one acetoxy group at $\delta 2.0$ and the presence of additional signals in the saturated region, in the ${ }^{1} \mathrm{H}$ NMR spectrum, led to the structure of compound $\mathbf{8}$ as the tetrahydrogenated alcohol derivative of vinhaticyl acetate 4 .

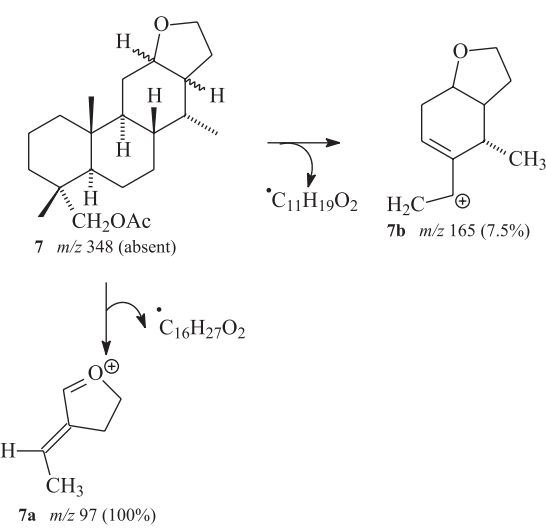

Scheme 2. Proposed fragmentation pattern in the mass spectrometer suggesting 7 as a tetrahydrofuran derivative.

Oxidation of compound $\mathbf{4}$ with Jones' reagent yielded a colorless solid, mp $181-184{ }^{\circ} \mathrm{C}$. The IR spectrum showed a free hydroxyl at $3330 \mathrm{~cm}^{-1}$, two carbonyl groups at 1730 and $1715 \mathrm{~cm}^{-1}$, and one trisubstituted double bond at $1640 \mathrm{~cm}^{-1}$. The ${ }^{13} \mathrm{C}$ NMR data at $\delta 173.6$ and $\delta 113.1$, and $\delta 5.56$ in the ${ }^{1} \mathrm{H}$ NMR, and yet a representative resonance related to the non hydrogenated hemiketal carbon at $\delta 106.5$, confirmed a $\gamma$-hydroxy- $\gamma$-butenolide moiety instead of a furan ring as in 4 . All these inferences were supported by the chemical shifts and comparative analysis with resonance data of active lactols derivatives from furan cassane diterpenes reported in the literature. ${ }^{6-8}$ Therefore, the structure of this product was determined to be the lactol 9 .

Upon hydrogenation, compound $\mathbf{5}$ yielded a colorless solid, mp $74-76^{\circ} \mathrm{C}$. The absence of signals in the lowfield 
region in ${ }^{1} \mathrm{H}$ NMR spectrum confirmed the reduction of the furan ring when compared with $\mathbf{5}$. The formation of a tetrahydrofuran derivative was confirmed through the ${ }^{13} \mathrm{C}$ NMR spectrum where was observed the absence of unsaturated carbon signals and the appearance of four additional signals in the region of saturated carbons: two methines at $\delta 78.1(\mathrm{C}-12)$ and $\delta 35.0(\mathrm{C}-13)$ and two methylenes at $\delta 30.0(\mathrm{C}-15)$ and $\delta 66.2(\mathrm{C}-16)$. Thus, the product must be the tetrahydrofuran derivative of methyl vinhaticoate, $\mathbf{1 0}$.

Compounds $\mathbf{2}$ to $\mathbf{1 0}$ were submitted to antibacterial and antifungal tests according to the general qualitative antimicrobial activity bioassay described by Hufford et al., ${ }^{9}$ as modified by Clark et al. ${ }^{10} \mathrm{~A}$ standard antibacterial agent, streptomycin sulfate, and a standard antifungal agent, amphotericin B, were included in each assay as positive controls. All of them showed only weak antimicrobial activity (Table 2 and 3 ).

\section{Experimental}

\section{General procedures}

Melting points were obtained on a Mettler PF-5. IR spectra were recorded using a Perkin Elmer 720 or 1320 spectrometers. The mass spectra were obtained on a HP 5995-A mass spectrometer by electron impact ionization $(70 \mathrm{eV}) .{ }^{1} \mathrm{H}$ NMR spectra at $60 \mathrm{MHz}$ where recorded on a Varian EM-360 while the ${ }^{1} \mathrm{H}$ NMR spectra at $300 \mathrm{MHz}$ and ${ }^{13} \mathrm{C}$ NMR spectra at $75 \mathrm{MHz}$ were recorded on a Varian XL-300 spectrometer; chemical shifts were given in $\delta$ (ppm) relative to TMS as an internal standard.

\section{Plant material}

Trunk heartwood of Plathymenia reticulata was collected in Crato, Ceará and the plant material was

Table 2. Antibacterial activity ${ }^{\mathrm{a}}$ of compounds $\mathbf{1}, \mathbf{3}$ to $\mathbf{1 0}$

\begin{tabular}{|c|c|c|c|c|c|c|c|c|c|c|}
\hline \multirow[t]{2}{*}{ Compound $^{\mathrm{b}}$} & \multicolumn{2}{|c|}{ E. coli } & \multicolumn{2}{|c|}{ S. aureus } & \multicolumn{2}{|c|}{ P. aeruginosa } & \multicolumn{2}{|c|}{ B. subtilis } & \multicolumn{2}{|c|}{ M. smegmatis } \\
\hline & 24 & 48 & 24 & 48 & 24 & 48 & 24 & 48 & 24 & 48 \\
\hline 1 & 1 & 1 & 1 & 1 & - & - & 2 & - & 1 & 2 \\
\hline 3 & 1 & 1 & 4 & 4 & 1 & - & 1 & 1 & 6 & 6 \\
\hline 4 & 1 & 1 & 1 & 1 & - & - & 3 & 2 & \pm & 2 \\
\hline 5 & - & - & 2 & 1 & 1 & \pm & 3 & 2 & \pm & 2 \\
\hline 6 & - & - & \pm & 1 & - & - & - & - & \pm & \pm \\
\hline 7 & \pm & 1 & \pm & \pm & 1 & 1 & - & - & 2 & 2 \\
\hline 8 & - & - & 2 & 2 & \pm & - & \pm & - & 4 & 4 \\
\hline 9 & \pm & 2 & 4 & 3 & 2 & 2 & 3 & 3 & 5 & 5 \\
\hline 10 & - & - & - & - & - & 3 & 2 & 2 & 4 & 5 \\
\hline Streptomycin sulfate ${ }^{c}$ & 7 & 6 & 8 & 7 & 6 & 5 & 9 & 8 & 20 & 18 \\
\hline
\end{tabular}

antibacterial activity was recorded as the width of the inhibition zone measured from the edge of the agar well to the edge of the inhibition zone after $24 \mathrm{~h}$ and $48 \mathrm{~h}$ of incubation using the following code: (-): no activity; ( \pm ) questionable; (numerals): average radius, in millimeters, of definite inhibition; ${ }^{\mathrm{b}}$ Compounds were prepared in a solution $1 \mathrm{mg} \mathrm{mL}{ }^{-1} \mathrm{EtOH} ;{ }^{\mathrm{c}} 1 \mathrm{mg} \mathrm{mL}^{-1} 25 \% \mathrm{EtOH}$.

Table 3. Antifungal activitya of compounds $\mathbf{1}, \mathbf{3}$ to $\mathbf{1 0}$

\begin{tabular}{|c|c|c|c|c|c|c|c|c|}
\hline \multirow[t]{2}{*}{ Compound $^{\mathrm{b}}$} & \multicolumn{2}{|c|}{ S. cerevisiae } & \multicolumn{2}{|c|}{ C. neoformans } & \multicolumn{2}{|c|}{ A. flavus } & \multicolumn{2}{|c|}{ T. mentagrophytes } \\
\hline & 48 & 72 & 48 & 72 & 48 & 72 & 48 & 72 \\
\hline 1 & 2 & 2 & - & - & - & - & 1 & 1 \\
\hline 3 & 2 & 2 & 5 & 3 & \pm & - & 4 & 3 \\
\hline 4 & 2 & 2 & \pm & - & - & - & 1 & 1 \\
\hline 5 & 3 & 3 & - & - & - & - & 2 & 1 \\
\hline 6 & 1 & 1 & - & - & - & - & 1 & 1 \\
\hline 7 & 3 & 3 & \pm & \pm & - & - & 4 & 3 \\
\hline 8 & 3 & 3 & 3 & 3 & - & - & 3 & 2 \\
\hline 9 & 3 & 3 & \pm & - & - & - & 3 & 2 \\
\hline 10 & 2 & 2 & 1 & 1 & - & - & 1 & 2 \\
\hline Amphotericin $\mathrm{B}^{\mathrm{c}}$ & 11 & 8 & 13 & 11 & 5 & 4 & 9 & 7 \\
\hline
\end{tabular}

${ }^{a}$ Antifungal activity was recorded as the width of the inhibition zone measured from the edge of the agar well to the edge of the inhibition zone after $48 \mathrm{~h}$ and $72 \mathrm{~h}$ of incubation using the following code: (-): no activity; ( \pm ) questionable; (numerals): average radius, in millimeters, of definite inhibition; ${ }^{\mathrm{b}}$ Compounds were prepared in a solution $1 \mathrm{mg} \mathrm{mL}{ }^{-1} \mathrm{EtOH}$; ${ }^{\mathrm{c}} 1 \mathrm{mg} \mathrm{mL}^{-1} 25 \% \mathrm{EtOH}$ 
identified by Dr. Afrânio G. Fernandes (Universidade Federal do Ceará). A voucher specimen number 9014 has been deposited in the Herbário Prisco Bezerra of the Departamento de Biologia, Universidade Federal do Ceará, Brazil.

\section{Extraction and isolation of the constituents}

The air dried heartwood $(4.0 \mathrm{~kg})$ was powdered and extracted with hexane $(3 \times 12.0 \mathrm{~L})$ at room temperature. The solvent was removed under reduced pressure yielding a viscous yellow oil (130.0 g). Part of the hexane extract (100.0 g) was coarsely partitioned on silica gel (400.0 g) column chromatography and eluted with hexane, $\mathrm{CHCl}_{3}$ and EtOAc. The fractions obtained were combined according to the TLC analysis and the less polar fractions, F1-5, F-8, F-10 and F-11, showed to be of further interest. Filtration under vacuum of the F1-5 fraction yielded compound 4 (5.6 g) as a pale yellow solid. Upon rechromatography of the filtrate on silica gel using hexane, compound 5 ( $0.3 \mathrm{~g})$ was obtained as a pale yellow solid.

Fraction F-8 (19.1 g) was re-chromatographed on silica gel $(20.0 \mathrm{~g})$, using hexane- $\mathrm{CHCl}_{3}, \mathrm{CHCl}_{3}$ and EtOAc as eluting solvents. The fractions obtained were combined according to the TLC analysis and from F-8 (3-23) fraction the compound 3 (1.56g) was isolated as a colorless oil.

After successive chromatography on silica gel (75.0 g) of fraction F-10 (4.1 g), and elution with hexane, $\mathrm{CHCl}_{3}$ and AcOEt, the fractions obtained were combined according to the TLC analysis. Compound $\mathbf{1}(0.3 \mathrm{~g})$ was obtained from fraction F-10 (38-61) (0.86 g) as a colorless solid.

16,18-diacetoxycass-13(15)-ene (1). Colorless solid; mp 69-71 ${ }^{\circ} \mathrm{C}$; IR $v_{\max } / \mathrm{cm}^{-1} 2900,2840,1720,1710,1660$, 1440, 1360, 1230, 1215, 1020, 785, 760 (KBr); ${ }^{1} \mathrm{H}$ NMR $\left(300 \mathrm{MHz}, \mathrm{CDCl}_{3}\right) \delta 5.33(\mathrm{t}, J 7.0 \mathrm{~Hz}, 1 \mathrm{H}), 4.36(\mathrm{~d}, J 7.0 \mathrm{~Hz}$, 2H), $3.70(\mathrm{~d}, J 11 \mathrm{~Hz}, 1 \mathrm{H}), 3.55$ (d, J $11.0 \mathrm{~Hz}, 1 \mathrm{H}), 1.96$ (s, $3 \mathrm{H}), 1.93$ (s, 3H), 0.93 (d, J 7.0Hz, 3H), 0.83 (s, 6H); ${ }^{13} \mathrm{C}$ NMR $\left(\mathrm{CDCl}_{3}, 75 \mathrm{MHz}\right)$ : see Table 1; GC/EIMS (70 eV) $\mathrm{m} / \mathrm{z} 390\left(\mathrm{M}^{+}{ }^{+}, 2 \%\right), 330$ (19), 257 (79), 255 (19), 175 (28), 161 (35), 159 (19), 148 (23), 135 (62), 133 (62), 131 (20), 123 (27), 121 (44), 119 (35), 109 (44), 107 (78), 105 (53), 97 (21), 95 (52), 93 (77), 91 (60), 81 (100), 79 (78), 69 (43), 67 (69), 55 (81), 53 (22).

Fraction F-11 (21.63 g), was re-chromatographed on silica gel $(100.0 \mathrm{~g})$ using hexane- $\mathrm{CHCl}_{3}, \mathrm{CHCl}_{3}$ and $\mathrm{CHCl}_{3}-$ EtOAc as eluting solvents. After combination of the fractions according to the TLC analysis, compound 2 (0.8 g) was obtained from fraction F-11 (22-76) $(5.7 \mathrm{~g})$, as a colorless oil.

16-hydroxy-18-acetoxycass-13(15)-ene (2). Yellow oil;
IR $v_{\max } / \mathrm{cm}^{-1}: 3400,2920,2860,1715,1660,1460,1440$, 1380, 1235, 1030, 795 (film); ${ }^{1} \mathrm{H} \mathrm{NMR}\left(60 \mathrm{MHz}, \mathrm{CDCl}_{3}\right)$ : 5.23 ( t, J 7.0 Hz, 1H), 3.93 (d, J 7.0 Hz, 2H), 3.66 (ABq, $J$ $11.0 \mathrm{~Hz}, 2 \mathrm{H}), 2.01$ (s, 3H), 1.16 (d, J 7.0 Hz, 3H), 0.86 (s, 6H); GC/EIMS (70 eV) m/z $348\left(\mathrm{M}^{+} 2.0 \%\right.$ ), 346 (23), 328 (26), 253 (50), 251 (35), 221 (22), 189 (26), 187 (58), 175 (49), 173 (37), 171 (26), 161 (59), 159 (53), 148 (23), 147 (64), 135 (62), 133 (78), 132 (78), 131 (63), 121 (87), 120 (58), 119 (78), 117 (25), 109 (75), 108 (41), 107 (89), 105 (51), 85 (91), 93 (58), 81 (100), 60 (93).

Reduction of $1 . \mathrm{LiAlH}_{4}(0.03 \mathrm{~g})$ was added to a solution of $1(0.1 \mathrm{~g})$ in dry $\mathrm{Et}_{2} \mathrm{O}(2.0 \mathrm{~mL})$ under stirring at room temperature for $3 \mathrm{~h}$. The mixture was treated following usual work-up and the reaction products were chromatographed on a silica gel column using hexane/ $\mathrm{CHCl}_{3}(1: 1)$ as eluting solvents, to afford $\mathbf{6}$ as colorless needles $(0.056 \mathrm{~g}): \mathrm{mp} 122-125{ }^{\circ} \mathrm{C}$; IR $v_{\max } / \mathrm{cm}^{-1}: 3400$, 2970, 2890, 1660, 1480, 1400, 1060 (film); ${ }^{1} \mathrm{H}$ NMR (60 $\left.\mathrm{MHz}, \mathrm{CDCl}_{3}\right): 5.33(\mathrm{t}, J 7.0 \mathrm{~Hz}, 1 \mathrm{H}), 4.03(\mathrm{~d}, J 7.0 \mathrm{~Hz}, 2 \mathrm{H})$, 3.20 (d, $J 11.0 \mathrm{~Hz}, 1 \mathrm{H}), 3.00$ (d, J $11.0 \mathrm{~Hz}, 1 \mathrm{H}), 0.93$ (d, $J$ $7.0 \mathrm{~Hz}, 3 \mathrm{H}), 0.83$ (s, 3H), 0.77 (s, 3H).

Acetylation of $\mathbf{2}$. Compound 2 (0.3 g) was dissolved with pyridine $(2.0 \mathrm{~mL})$ and $\mathrm{Ac}_{2} \mathrm{O}(2.0 \mathrm{~mL})$ and stirred at room temperature overnight. Subsequent workup afforded a colorless solid (0.32 g) that was chromatographed using hexane/EtOAc (3:1) as eluent. The acetylated product was identified by direct comparison ( $\mathrm{mp},{ }^{1} \mathrm{H} \mathrm{NMR}$ ) with 16,18 diacetoxycass-13(15)- ene (1).

Reduction of $\mathbf{2}$. Compound $\mathbf{2}$ (0.8 g) was dissolved in dry $\mathrm{Et}_{2} \mathrm{O}(10.0 \mathrm{~mL}), \mathrm{LiAlH}_{4}(0.3 \mathrm{~g})$ was added to a solution and the mixture was stirred at room temperature for $3 \mathrm{~h}$. After usual workup, the reaction products were chromatographed on a silica gel column using hexane/EtOAc (3:1) as eluting solvents, to afford 6 (0.62 g). This compound was characterized after direct comparison ( $\mathrm{mp}$, TLC co-chromatography and ${ }^{1} \mathrm{H}$ NMR) with those obtained previously.

Hydrogenation of 4. Compound 4 (0.1 g) was dissolved in $\mathrm{MeOH}(10.0 \mathrm{~mL})$ and added to a suspension containing $\mathrm{Pd} / \mathrm{C}(0.015 \mathrm{~g})$, that has been saturated with $\mathrm{H}_{2}$. The mixture was stirred at room temperature during overnight. Workup in the usual way afforded a residue $(0.09 \mathrm{~g})$ containing two products that were separated by $\mathrm{SiO}_{2}$ chromatography using hexane/ $\mathrm{CHCl}_{3}(3: 1)$ as eluting solvents. The less polar product, compound 7 (36.0 $\mathrm{mg})$, was obtained as a pale yellowish oil. IR $v_{\max } / \mathrm{cm}^{-1}: 2880,2800,1710,1440$, 1360, 1220, 1080, 1040 (film); ${ }^{1} \mathrm{H}$ NMR (60 MHz, $\mathrm{CDCl}_{3}$ ): 3.66 (q, J $11.0 \mathrm{~Hz}, 2 \mathrm{H}), 2.03$ (s, 3H), 0.90 (d, J 7.0 Hz, 3H), $0.90(\mathrm{~s}, 6 \mathrm{H})$; GC/EIMS (70 eV) $\mathrm{m} / z$ ( $\mathrm{M}^{{ }^{+}}$, absent), 275 (42), 198 (30), 175.0 (24), 161.0 (24), 198.0 (30), 175 (24), 165 (7.5), 161 (24), 149 (61), 147 (25), 135 (37), 123 (50), 109 
(64), 107 (65), 97 (100), 95 (82), 93 (65), 55 (95). The more polar product, compound $8(45.0 \mathrm{mg})$, was obtained as a colorless solid: mp $124-125^{\circ} \mathrm{C}$; IR $v_{\max } / \mathrm{cm}^{-1}: 3390,2900$, 2890, 1480, 1470, $13701080(\mathrm{KBr}) ;{ }^{1} \mathrm{H}$ NMR $(60 \mathrm{MHz}$, $\left.\mathrm{CDCl}_{3}\right): 3.53(\mathrm{~m}, 2 \mathrm{H}), 3.03(\mathrm{q}, 2 \mathrm{H}, J 11.0 \mathrm{~Hz}), 0.83(\mathrm{~d}, 3 \mathrm{H}, J$ $11.0 \mathrm{~Hz}), 0.83$ (s, 3H), 0.72 (s, 3H); ${ }^{13} \mathrm{C} \mathrm{NMR}(75 \mathrm{MHz})$ : see Table 1; GC/EIMS (70 eV) m/z, $306\left(\mathrm{M}^{+}, 9.3 \%\right), 275(65)$, 193 (35), 175 (29),161 (31), 149 (81), 147 (34), 121 (42), 97 (100), 79 (36), 69 (53), 55 (62).

Oxidation of $4.5 .0 \mathrm{~mL}$ of Jones' reagent was added slowly to a solution of $\mathbf{4}(0.5 \mathrm{~g})$ in acetone $(10.0 \mathrm{~mL})$. The mixture was stirred at $0{ }^{\circ} \mathrm{C}$ during 30 minutes. Usual workup and $\mathrm{SiO}_{2}$ column chromatography using hexane/ $\mathrm{CHCl}_{3}$ (2:1), yielded compound $\mathbf{9}(0.2 \mathrm{~g})$ as a colorless solid: $\mathrm{mp}$ 181-183 ${ }^{\circ} \mathrm{C}$; IR $v_{\max } / \mathrm{cm}^{-1}: 3330,2940,2900,1730,1715$, 1640, 1430, 1220, $1120(\mathrm{KBr}) ;{ }^{1} \mathrm{H} \mathrm{NMR}\left(60 \mathrm{MHz}, \mathrm{CDCl}_{3}\right)$ : $5.56(\mathrm{~s}, 1 \mathrm{H}), 3.66(\mathrm{q}, 2 \mathrm{H}, J 11.0 \mathrm{~Hz}), 2.50(\mathrm{t}, 2 \mathrm{H}, J 10.0 \mathrm{~Hz})$, 2.10 (s, 3H), 1.15 (d, 3H, J 7.0 Hz), 0.86 (s, 6H); ${ }^{13} \mathrm{C} \mathrm{NMR}$ (75 MHz): see Table 1; GC/EIMS (70 eV) m/z: ( $\mathrm{M}^{+}$, absent), 189 (20), 162 (22), 160 (100), 149 (29), 121 (27), 109 (43), 95 (60), 93 (41), 91 (50), 81 (78), 79 (45), 69 (3), 53 (32).

Hydrogenation of $\mathbf{5}$. Compound $5(0.47 \mathrm{~g})$ was dissolved in $\mathrm{MeOH}$ and added to a suspension containing $\mathrm{Pd} / \mathrm{C}(0.05 \mathrm{~g})$ in $\mathrm{MeOH}(30.0 \mathrm{~mL})$, that was previously saturated with $\mathrm{H}_{2}$. The mixture was stirred at room temperature during overnight. Usual work up and $\mathrm{SiO}_{2}$ column chromatography using hexane/ $\mathrm{CHCl}_{3} 1: 1$ yielded compound $\mathbf{1 0}(0.35 \mathrm{~g})$ as a colorless solid: $\mathrm{mp} 74-76{ }^{\circ} \mathrm{C}$; IR $v_{\max } / \mathrm{cm}^{-1}: 2870,2850,1715,1450,1395,1260,1150$ $(\mathrm{KBr}) ;{ }^{1} \mathrm{H}$ NMR (60 MHz, $\mathrm{CDCl}_{3}$ ): 3.63 (s, 3H), 1.20 (s, $3 \mathrm{H}), 0.86(\mathrm{~d}, J 7.0 \mathrm{~Hz}, 3 \mathrm{H}), 0.88(\mathrm{~s}, 3 \mathrm{H}) ;{ }^{13} \mathrm{C}$ NMR $(75$ MHz): see Table 1 .

\section{Acknowledgements}

The autors are grateful to Dr. Francisco J. A. Matos and Dr. Afranio G. Fernandes (Universidade Federal do Ceará) for plant collection and identification and to Dr. J. D. McChesney and Dr. C. D. Hufford (University of MississipiUSA) for the antimicrobial tests and 300/75 $\mathrm{MHz}$ NMR, data respectively. This work was financially supported by grants from CNPq/CAPES/FINEP/PADCT/FUNCAP/ PRONEX.

\section{References}

1. King, T.J.; Rodrigo, S.; Chem. Commun. 1967, 575.

2. Matos, F.J.A.; Craveiro, A.A., Maurera, M.A.M.A.; J. Nat. Prod. 1984, 47, 581.

3. Maurera, M.A.M.A.; Matos, F.J.A.; Craveiro, A.A.; Proc. Anais do VI Simpósio de Plantas Medicinais do Brasil, Fortaleza, Brazil, 1980.

4. Godoy, R. L.; Lima, P. D. D. P.; Pinto, A. C.; Aquino Neto, F. R.; Phytochemistry 1989, 28, 642.

5. Wenkert, E.; Cochran, D. W.; Hagaman, E. W.; Schell, F. M.; Neuss, N.; Katner, A. S.; Potier, P.; Kan, C.; Plat, M.; Koch, M.; Mehri, H.; Poisson, J.; Kunesch, N.; Rolland, Y.; J. Am. Chem. Soc. 1973, 95, 4990.

6. Fang, J.; Lang, C.; Chen, W.; Cheng, Y.; Phytochemistry 1991, 30, 2793.

7. Ahmed, M.; Ahmed, A. A.; Phytochemistry 1990, 29, 2715.

8. Mahajan, J. R.; Monteiro, M. B.; J. Chem. Soc., Perkin Trans I 1973, 520.

9. Hufford, C. D.; Funderburk, M. J.; Robertson, L. W.; J. Pharm. Sci. 1975, 64, 789.

10. Clark, A. M.; El-Feraly, F. S.; Li, W., S.; J. Pharm. Sci 1981, $70,951$. 